\title{
Palliative Radiation Therapy for Metastatic
} Cancer

National Cancer Institute

\section{Source}

National Cancer Institute. Palliative Radiation Therapy for Metastatic Cancer. NCI

Thesaurus. Code C104988.

Radiation therapy given as palliative treatment to a patient with metastatic cancer. 